\title{
Radial Head Fractures in Adults
}

Omar Mourafiq*, Jalal Elmekkaoui, Jalal Boukhriss, Bouchaib Chefry, Driss Benchebba, Mostapha Boussouga

Department of Orthopaedic Surgery and Traumatology II, Mohamed V Military Hospital of Rabat, Faculty of Medicine and pharmacy of Rabat, Mohamed V University, Rabat 10000, Morocco

DOI: $10.36347 /$ sasjs.2020.v06i05.003

| Received: 01.05.2020 | Accepted: 09.05.2020 | Published: 16.05.2020

*Corresponding author: Omar Mourafiq

\section{Abstract}

Objectives: To study the epidemiological, anatomopathological, diagnostic, therapeutic and evolutionary aspects of patients with a radial head fracture and compare our results with those of the literature. Introduction: Radial head fractures are articular fractures involving the head and/or neck of the radius; they are common in young persons. These fractures pose diagnostic and therapeutic problems. Osteosynthesis of the radial head allows early post-operative rehabilitation. If osteosynthesis is not possible, radial head prosthesis is discussed. Materials and methods: Our series includes 10 Men and six Women with an average age of 41 years, collected over a period of five years from 2014 to 2019 in the department of Orthopaedic Surgery and Traumatology II of the Mohamed V Military Hospital of Rabat. Most of the patients were victims of falls or road accidents. Type II fractures were the most common in $50 \%$ of cases. Seven patients had associated lesions of the homolateral upper limb. Herbert's screw osteosynthesis was used in $87.5 \%$ of our patients. Arthroplastic resection was performed in two patients. No radial head prosthesis was performed in our series. The principle of early mobilization was respected for all our patients. Results: The average decline in our series was 13 months; the evaluation of the results was based on the MAYO CLINIC score. Functional results were excellent in $37.5 \%$ of cases, good in $37.5 \%$ of cases, average in $25 \%$ of cases. Complications found were: infection in a patient, elbow stiffness in a patient and algodystrophy in a patient. Conclusion: Radial head fractures are quite common. Most are the result of functional treatment or stable direct osteosynthesis. The radial head prosthesis fits perfectly into the therapeutic strategy for multifragmentary radial head fractures that are not accessible to reliable osteosynthesis.

Keywords: Radial head - Fracture - Osteosynthesis - prosthesis.

Copyright @ 2020: This is an open-access article distributed under the terms of the Creative Commons Attribution license which permits unrestricted use, distribution, and reproduction in any medium for non-commercial use (NonCommercial, or CC-BY-NC) provided the original author and source are credited.

\section{INTRODUCTION}

Radial head fractures represent $33 \%$ of elbow fractures and 2 to $5 \%$ of all upper limb fractures [1]. Simple, isolated, non-displaced fractures do not require surgical treatment, while displaced fractures require stable osteosynthesis $[2,3]$. When osteosynthesis is not possible, the therapeutic alternatives are simple resection or radial head arthroplasty $[4,5]$. Due to the frequent association of ligament injuries, radial head resection may reveal frontal instability of the elbow and destabilization of the anti-brachial frame $[6,7]$.

\section{MATERIALS AND METHODS}

This is a retrospective study of 16 cases of radial head fracture, treated in the department of Orthopaedic Surgery and Traumatology II of the Mohamed V Military Hospital of Rabat, for a period of five years from 2014 to 2019 . The study methods were based on the exploitation of medical records with data collection on clinical examination, radiological, surgical data and evolution in these patients.
This study involved 10 men and 6 women with an average age of 41 years. The right side was affected in $50 \%$ of the cases. No bilateral damage was found in our series. Falling is the most frequent etiology $(63 \%$ of cases), followed by road accidents in $37 \%$ of cases. The modified MASON classification has been adopted. Type II fractures were the most observed in $50 \%$ of cases. In our study no skin openings were noted. Seven patients had associated lesions of the homolateral upper limb.

The procedure was performed 11 times under general anesthesia, while a locoregional anesthesia (Plexus block) was performed in the remaining patients. The treatment was surgical in all our patients. The posterolateral approach of CADENAT was the most used $(63 \%)$, the lateral approach of Kocher was used in $37 \%$ of cases. Herbert screw osteosynthesis was used in $87.5 \%$ of our patients (Figure-1). Arthroplastic resection was performed in two patients. No radial head prosthesis was performed in our series. Associated 
lesions were treated at the same time of surgery depending on the type of lesion (Figure-2). For patients with an isolated radial head fracture, mobilization was performed on the third post-operative day after a short 48 hours analgesic immobilization, followed by prolonged, passive then active rehabilitation.

\section{RESULTS}

Functional results were studied based on the clinical criteria proposed by the MAYO CLINIC classification. Functional and anatomical results were excellent in $37.5 \%$ of cases, good in $37.5 \%$ of cases and average in $25 \%$ of cases. We found $60 \%$ excellent results and $40 \%$ good results in patients with isolated radial head fractures. For those with associated lesions, we found $38 \%$ good results, $62 \%$ average results. The results were satisfactory in patients treated with Herbert screws, $38 \%$ excellent and $62 \%$ good. For patients treated by radial head resection, the results were excellent in $25 \%$ of cases, good in $25 \%$ and average in $50 \%$. The postoperative complications were of three types: septic complications in a patient who was controlled by antibiotic treatment with local care, stiffness of the elbow in a patient who initially had an unfortunate triad of the elbow, the stiffness was treated by arthrolysis of the elbow with good evolution and a case of algodystrophy whose evolution was favorable under physiotherapy.

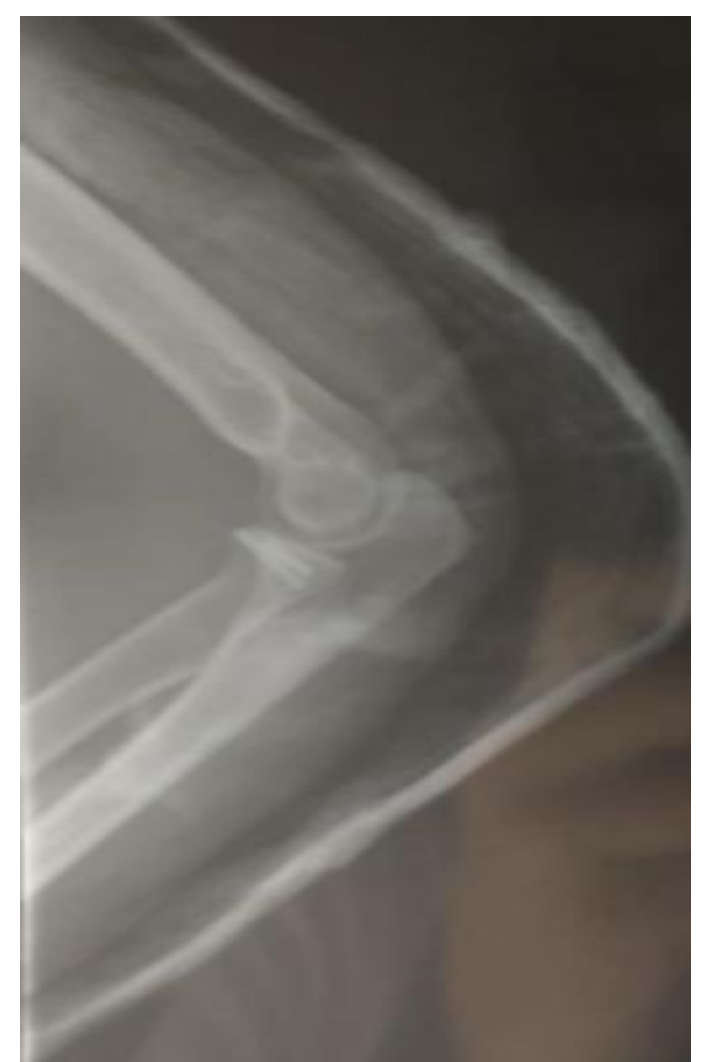

Fig-1: Reduction and Herbert screwing of type II radial head fracture

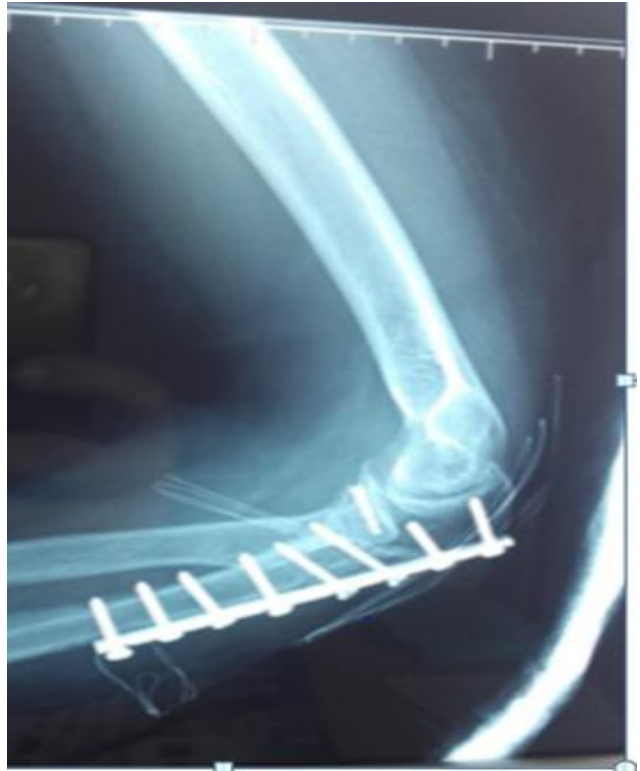

Fig-2: Radial head fracture associated with proximal ulna fracture, plate osteosynthesis for the ulna and Herbert screwing for the radial head fracture

\section{DISCUSSION}

Radial head fractures are quite common (20\% of elbow injuries) [8]. They most often result from an indirect mechanism, falling on the hand in extension with the forearm in pronation [9]. Most are the result of functional treatment (in the absence of displacement) or stable direct osteosynthesis and repair of the associated injuries, found in nearly $80 \%$ of cases $[2,3]$. However, faced with a very comminuted fracture with the impossibility of obtaining stable fixation, prosthetic replacement has been proposed since the 1970's [8]. The average age in our series is 41 years, which is close to the data in the literature [10], this young age could be explained by the high rate of road accidents, which mainly concerns the youngest subjects.

The majority of the series report a male predominance ranging from $60 \%$ to $80 \%$ [10, 11], in our series we found the same phenomenon, where the male was reached in the proportion of $63 \%$ of the cases. All of our patients were admitted in the emergency room, the initial clinical examination allows the elimination of a major lesion involving the patient's vital prognosis, and the evaluation of the neurovascular and cutaneous state of the traumatized limb as well as searching for other fractures in the other limbs, which may influence surgical management. We have performed standard x-rays of all our patients, of the elbow front and side, shoulder and wrist homolateral. A preoperative CT scan including frontal and sagittal reconstructions may be necessary to determine the size of the fragment and the existence of an overturned joint fragment or in case of doubt about an associated lesion [12]. Type I fractures require functional treatment and type II fractures require reduction and stable osteosynthesis [2, 13]. Herbert's screw osteosynthesis was used in $87.5 \%$ of our patients. 
The radial head prosthesis is an alternative to difficult osteosynthesis or arthroplastic resection [8] Indeed, it has been shown that in the case of arthroplastic resection for type III multifragmentary fracture, proximal migration appears in almost $50 \%$ of cases, valgus deviation of the elbow in $30 \%$ of cases and, in the medium term, secondary humeroulnar osteoarthritis in $50 \%$ of cases [14].

Current implants (modular or monobloc, with or without a mobile cup) ensure mechanical stability close to that of a native radial head, but do not dispense with the treatment of any associated lesions (reinsertion of the radial collateral ligament, distal radio-ulnar stabilisation in the case of Essex-Lopresti syndrome [8].

\section{CONCLUSION}

Radial head fractures are quite common. Most are the result of functional treatment or direct osteosynthesis. Comminuted fracture of the radial head may compromise the stability of the elbow and antibrachial frame. When osteosynthesis is not possible, the radial head prosthesis can reconstruct the lateral column and restore frontal stability of the elbow and horizontal stability of the forearm.

\section{REFERENCES}

1. Aude Q, Jean-Claude C, Raymond-Gilbert D. Fractures de la Tête Radiale. Rééducation de l'appareil locomoteur. Tome 2. Membre supérieur (C)2008, 177-189

2. Duckworth AD, Wickramasinghe NR, Clement ND, McQueen MM. Long-term outcomes of isolated stable radial head fractures. JBJS. 2014 Oct 15;96(20):1716-23.

3. van Riet RP, Morrey BF, O’Driscoll SW, Van Glabbeek F. Associated injuries complicating radial head fractures: a demographic study. Clinical Orthopaedics and Related Research $®$. 2005 Dec 1;441:351-5.

4. King GJ. Management of comminuted radial head fractures with replacement arthroplasty. Hand clinics. 2004 Nov 1;20(4):429-41.
5. Hotchkiss RN. Displaced fractures of the radial head: internal fixation or excision?. JAAOSJournal of the American Academy of Orthopaedic Surgeons. 1997 Jan 1;5(1):1-0.

6. Jensen SL, Olsen BS, Tyrdal S, Søjbjerg JO, Sneppen O. Elbow joint laxity after experimental radial head excision and lateral collateral ligament rupture: efficacy of prosthetic replacement and ligament repair. Journal of shoulder and elbow surgery. 2005 Jan 1;14(1):78-84.

7. Morrey BF, Chao EY, Hui FC. Biomechanical study of the elbow following excision of the radial head. The Journal of bone and joint surgery. American volume. 1979 Jan;61(1):63-8.

8. Bonnevialle N. Place de l'arthroplastie dans les fractures récentes de la tête radiale chez l'adulte. Conférences d'enseignement 2015, Elsevier Masson SAS. (C) 2015

9. Van Riet RP, Van Glabbeek F, Morrey BF. Radial head fracture. In: Morrey BF, editor. The elbow and its disorders. 4th ed Philadelphia: Saunders Elsevier; 2009, 359-81.

10. Duparc F, Tobenas Ac, Neveu C. fractures et fractures luxations de la tête radiale, série multicentrique GEEC98. Dans fractures de la tête radiale, Sauramps médical, 1999:61-72.

11. Asencio G, Arakelian F, Vidal J, Dossa J, Bertin R. L'ostéosynthèse des fractures de la tête radiale chez l'adulte. Revue de chirurgie orthopédique et réparatrice de l'appareil moteur. 1990;76(7):44550.

12. Judet T. Fractures de la tête radiale chez l'adulte. Cahiers d'enseignement de la SOFCOT. 2005;87:77-93.

13. Judet T. Fractures de la tête radiale chez l'adulte. In: Conférence d'enseignement 2005. Cahier d'enseignement de la Sofcot no 87. Paris: Expansion Scientifique; 2005. 77-93.

14. Mikíc ZD, Vukadinovíc SM. Late results in fractures of the radial head treated by excision. Clin Orthop Relat Res, 1983;181:220-8. 